\title{
BLAME AND WRONGDOING
}

\author{
JESSICA BROWN
}

jab3o@st-andrews.ac.uk

\begin{abstract}
The idea that one can blamelessly violate a norm is central to ethics and epistemology. The paper examines the prospects for an account of blameless norm violation applicable both to norms governing action and norms governing belief. In doing so, I remain neutral on just what are the norms governing action and belief. I examine three leading suggestions for understanding blameless violation of a norm which is not overridden by another norm: (I) doxastic accounts; (2) epistemic accounts; and (3) appeal to expected value. We see that all of these accounts face problems when understood as accounts of blameless norm violation applicable to both belief and action. This leaves a variety of options including (I) seeking an alternative account of blameless norm violation common to belief and action; (2) concluding that we cannot determine the correct account of blameless norm violation independently of what are the norms of belief; and (3) abandoning the project of finding a common account of blameless norm violation common to ethics and epistemology.
\end{abstract}

\section{INTRODUCTION}

The notion of blame has long been important to ethics and practical reasoning. In particular, it's been recognised that someone might blamelessly violate a norm. For instance, someone might blamelessly violate the norm of promise keeping: she might blamelessly fail to keep her promise to pick up her friend from the airport, because she is blamelessly wrong about which airport she's arriving at (perhaps her friend misinformed her). More recently, the notion of blame has become of increasing interest to epistemology. In part, this is because of the increasing interest in the idea of epistemic norms, the idea that certain epistemic conditions, say knowledge, are the norm for belief, assertion or practical reasoning. Just as in the ethical case, we might expect cases in which such epistemic norms may be blamelessly violated. Indeed, given the general failure of luminosity, there will be cases in which the relevant epistemic condition, say knowledge, obtains but one isn't in a position to know that it obtains; and, cases in which the relevant epistemic condition does not obtain, but one isn't in a position to know that it doesn't obtain (Williamson 2000). One might expect such failures of luminosity to give rise to cases of blameless norm-violation and blameworthy norm-conformity (e.g. Williamson 2000; Hawthorne and Srinivasan 2013). Thus, epistemologists are increasingly interested in the notion of being blameworthy and how it diverges from norm-conformity.

Given the importance of the notion of blameless norm-violation in both ethics and epistemology, it seems that those working in each area would be well advised to consider 
work on blameless norm-violation in the other. For, an account of blameless norm violation which seems attractive in one area might be shown to be problematic by considerations from the other. In particular, we might hope for a common account of blameless norm violation which can be used in both domains. In that case, it is important that any proposed account of blameless norm violation works for both domains. This paper seeks to examine the prospects for such a common account of blameless norm violation.

Of course, in both ethics and epistemology, it's controversial just what are the norms governing action and belief. So, one might hope to provide an account of blameless norm violation without first settling what are the norms in ethics and epistemology. However, one of the lessons of the paper is that this hope may be forlorn. In particular, I will argue that certain approaches to explaining what it is to blamelessly violate a norm work on some accounts of the norm for belief but fail on others. So, it may not be possible to provide an account of blameless norm violation without first settling what is the norm for belief.

In the next section, I set up the issue to be discussed more precisely. Then, in the following sections, I examine what I take to be some of the leading suggestions for how to understand blameless norm violation. These include appeal to the belief that one's not violating the norm; appeal to having a certain epistemic status with respect to whether one's violating the norm (justification, evidence, being in a position to know); and, appeal to decision theory. The overall conclusion will be that each of the views is problematic when understood as an attempt to explain blameless violation of norms applicable to belief and action. The discussion does not consider all possible accounts of blameless norm violation. ${ }^{\text {I }}$ So, it doesn't establish that there cannot be a common account of blameless norm violation for both norms of action and belief. Nevertheless, it raises difficulties for several kinds of approach.

\section{NORMS, EXCUSES, AND OUGHT}

In attempting to provide a common account of blameless norm violation an immediate problem arises from the fact that there is disagreement in the literature about how many evaluative notions we need to appeal to. Some suggest that we can get an adequate account of blameless norm violation by using just two main notions, the notion of what one objectively ought to do and the notion of excuse. For example, suppose that one objectively ought to perform a certain action if and only if it maximises happiness. Nonetheless, a subject might not be judged harshly if her action fails to maximise happiness if she reasonably believed it did maximise happiness. To accommodate the latter possibility, we might appeal to the notion of excuse. However, others hold that we need at least three notions for an adequate account of blameless norm violation. In addition to the notions of what one objectively ought to do and excuse, we need the notion of what one subjectively ought to do, where the latter cannot be simply identified with believing that one's action maximises happiness (e.g. Zimmerman 20I4). Analogously, some have recently suggested that epistemology can understand blameless norm violation

I In particular, the discussion excludes appeals to the quality of the subject's will (e.g. Mason 20 I 5), appeal to habits or virtues, or appeal to dispositions (e.g. Sutton 2007; Williamson Forthcoming). I raise problems for appeal to dispositions in Brown Forthcoming. 
using just two notions, the notion of conforming to certain epistemic norms and the notion of being excused for failing to do so. For instance, suppose that the epistemic norm for belief is truth. We don't judge a subject harshly for falsely believing that $\mathrm{p}$ if, say, she reasonably thought that $\mathrm{p}$ was true. On a traditional approach, we might allow that the subject's false belief has a positive epistemic quality, say justification, where justification is understood to be distinct from excuse. However, recently, some have suggested that epistemology can operate without the traditional notion of justification and instead merely with the notions of being in conformity to epistemic norms, and being excused for failing to conform to epistemic norms (e.g. Sutton 2007; Littlejohn Forthcoming; Williamson Forthcoming; for criticism see Brown Forthcoming; Cohen and Comesaña 20I3, Forthcoming; Kelp Forthcoming).

In this paper, I shall attempt to avoid getting into the debate about whether we need two or three notions to make sense of blameless norm violation. In particular, I will leave it open whether we need a notion of what one subjectively ought to do, or justification, in addition to the notions of what one objectively ought to do and excuse. Thus, I'll be concerned with formulating the conditions for blameless norm violation, leaving it open whether such blamelessness always amounts to excuse, or whether it can sometimes amount to doing what one subjectively ought to do where that is distinct from excuse.

A second complication we need to accommodate is that there are, in principle, two kinds of ignorance which can lead one to blamelessly violate a norm, ignorance of the norm (normative ignorance) or ignorance of the facts of one's situation (factual ignorance). While there is widespread agreement that blameless factual ignorance excuses there is more controversy about whether blameless moral ignorance excuses. ${ }^{2}$ For moral ignorance, even if blameless, can indicate how bad one is. For instance, that someone is ignorant that inflicting pain on sentient creatures for fun arguably indicates how immoral they are (even if they are blamelessly ignorant of this given their unfortunate upbringing). Certainly, if they torture a baby for fun while ignorant that this is to violate a norm, it's not automatic that they are not to blame (e.g. Harman 20II; Mason 20I5). So, I will set aside normative ignorance to focus on factual ignorance, taking it in what follows that the subject is not ignorant of the relevant norm. ${ }^{3}$

A third complication is that there can be two main reasons why one is blameless in violating some norm. In some cases, one is blameless for violating a first norm because it is overridden by a second norm. For instance, one might be blameless for violating the norm of etiquette that one shouldn't leave the table until after everyone has finished eating in order to save the Queen from a terrorist attack. In other cases, one is blameless for violating a norm even though it is not overridden by any other norm. For instance, perhaps a doctor unintentionally kills a patient by giving her a blood transfusion where a nurse has malevolently put poison in the hospital's supply of blood. Under the right circumstances, the doctor would be blameless for violating the norm not to kill her patients. It is the

2 Some argue that blameless moral ignorance excuses just as blameless factual ignorance does, including Calhoun (1989), Rosen (2003, 2004), Fitzpatrick (2008), Zimmerman (2008), Levy (2009). Others deny this, including Harman (2OII), Mason (20I5) and Weatherson (Forthcoming).

3 Nonetheless, some of the conclusions of the article apply to alleged cases of blameless norm violation due to ignorance of the relevant norm. For example, the subsequent criticisms of accounts of blameless norm violation due to factual ignorance in terms of (blameless) lack of belief, or lack of knowledge could be extended to undermine accounts of blameless norm violation due to normative ignorance. 
second kind of case with which we will be concerned here. So, we will be concerned only with cases in which one is blameless for violating a non-overridden norm. Thus, we'll be examining possible replacements for $\mathrm{C}$ in the following schema:

Blameless: A subject is blameless for violating the non-overridden norm, $\mathrm{N}$, if and only if $\mathrm{C}$.

The schema should be understood to apply to norms governing both action and belief, and whatever the relevant source of normativity. In particular, we are seeking an account of blameless norm violation which can cover both epistemic norms and moral norms. ${ }^{4}$

A first suggestion for the condition $\mathrm{C}$ is belief. 5 We can quickly dismiss two variants of this view, both the suggestion that $\mathrm{C}$ is mere belief that one's not violating the relevant norm, or the suggestion that $\mathrm{C}$ is lack of belief that one is violating the norm. For example, suppose a teacher gives a peanut-rich dish to a known-to-be peanut-allergic child having read the ingredients list which mentions peanuts. The teacher isn't blameless if she simply refuses to believe the ingredients list and persists in believing the dish contains no peanuts. So, mere belief is insufficient (e.g. inter alia, Rosen 2003, 2004; Cohen and Comesaña 20I3a; Williamson 20г3 b: 9I). Further, lacking belief is not sufficient either. For example, the teacher would not be blameless for feeding a peanut-rich dish to a known-to-be peanut-allergic child in the situation in which she lacks belief that it contains peanuts because she suspends on the issue given that the evidence leaves it 50:50 whether it contains peanuts (e.g. Guerrero 2007; Peels 20IO, 20I4; Harman 20II).

A better suggestion is that $\mathrm{C}$ is reasonable belief. Perhaps, a subject is blameless for violating the non-overridden norm, $\mathrm{N}$, if and only if she reasonably believes she is not violating that norm (Williamson 2000; Hawthorne 2004). There are a number of different ways of cashing out this idea depending on how one understands reasonable belief. One way would be to try and understand reasonable belief in terms of standard epistemic statuses, such as evidence or justification. So, one might suggest that a reasonable belief is one which is justified, or supported by the evidence. ${ }^{6}$ An alternative idea might be to appeal to the idea of a non-culpable or blameless belief. In the next section, I explore the prospects for appeal to non-culpable belief, before turning in the subsequent section to explore the prospects for appeal to belief which is justified or supported by the evidence. While the discussion only concerns blameless violation of a non-overridden norm, I mainly leave the qualification that the norm is not overridden implicit.

4 Some may think that a further complication arises from cases of dilemmas in which, no matter what a subject does, what she does is wrong because she violates some norm or other. Such dilemma cases involve conflicting norms where it's not the case that one norm overrides the other. In one classic example, a young man faces the dilemma of whether to stay and look after his ageing mother or whether to join the army in order to help free his country from an oppressive invader. Whatever he does, he will violate one of his duties. Under the right circumstances, he might be blameless for being in such a dilemma. If so, we might think that such dilemmas can also generate cases of blameless wrongdoing. Those who understand dilemmas in this way may want to add a further condition ruling out such cases.

5 Some require that one not only be ignorant that one is violating a norm but act from this ignorance. For a recent discussion of different formulations of the acting from condition, see Weatherson (Forthcoming: Ch. 5).

6 Of course, someone who eschews the notion of justification would not want to explain blameless norm violation by appeal to that very notion. But, they could nonetheless appeal to some other epistemic status they accept, such as being probable on the evidence or being known, or being in a position to know. 


\section{NON-CULPABLE BELIEF}

Let's consider the idea that one's blameless in violating a norm if and only if one nonculpably falsely believes that one's not violating that norm. ${ }^{7}$ The adequacy of this account depends on how we understand non-culpable belief. A first idea would be to suggest that a non-culpable belief is a belief which doesn't violate epistemic norms. ${ }^{8}$ For instance, Rosen (2004) suggests that a norm violation is blameless if one non-culpably but falsely believes that one's not violating the relevant norm, where he explains non-culpable belief as belief that doesn't violate epistemic norms. Perhaps, then, it might be suggested that a nonculpable belief is a belief which doesn't violate the norm for belief. However, this suggestion faces an immediate difficulty given the popularity of factive accounts of the norm of belief. If the belief that one's not violating a norm, $\mathrm{N}$, excuses a violation of $\mathrm{N}$ then that belief is false. So, if the norm of belief entails truth then one has violated the norm of belief in having a false belief that one's not violating N. Indeed many suppose that the norm of belief is truth, or some truth-entailing property such as knowledge.

Someone might attempt to get around this problem by appealing to the distinction between the primary norm governing belief and derivative norms. For instance, those who think that truth is the primary norm for belief often hold that there is a derivative norm enjoining one to conform one's beliefs to the evidence. Perhaps, one could explain non-culpable false belief as a false belief which doesn't violate the derivative norm or norms for belief. So, the suggestion would be that one blamelessly violates a norm, N, if and only if one falsely believes that one's not violating $\mathrm{N}$ where this false belief does not violate the derivative norms for belief. We might hope that this account would deal with paradigm examples of blameless norm violation. Consider a well-intentioned teacher who knows she has a peanut-allergic child in her class but ends up giving the child a peanut-rich curry because it has been mislabelled by the school kitchen. It may seem plausible that the teacher is blameless for the norm violation because her evidence supports the false belief that the curry doesn't contain peanuts. In this way, we might hope that appeal

7 One might worry that one can blamelessly violate a norm without having any belief that one's not violating that norm. In particular, that one can blamelessly have a false belief without having any second-order belief about whether that belief violates the norm for belief. I'm sympathetic to this worry, which would also apply to the justified belief account discussed in the next section (see Brown Forthcoming). So it may seem initially more promising to explain blameless norm violation by appeal to its being probable on the evidence or one's having justification to believe that one's violating the norm, or one's being ignorant that one is violating it (whether that's understood as a lack of belief or a lack of knowledge). But we will see subsequently that these suggestions face difficulties too.

8 There are a range of different views about what it takes to non-culpably have a false belief which excuses a norm-violating action. Rosen (2003) suggests that a false belief is non-culpable only if it doesn't stem from an earlier knowing violation of epistemic norms. But examples from Moody-Adams (1994) and Fitzpatrick (2008) show that Rosen's requirement is too strong. For a subject may be blameworthy for acting from motivated ignorance which involves only the unwitting violation of epistemic norms. A more plausible suggestion is that ignorance is blameless only if it does not involve violating epistemic norms. Some suggest that one has a moral obligation to inform oneself about matters relevant to the moral permissibility of one's conduct (Rosen 2003: 63, note 3; 2004: 30I; Guerrero 2007). However, even if this idea seems plausible when we are interested in developing an account of blameless violation of the norms for action, it doesn't seem helpful when we are interested in developing an account of blameless norm violation which applies to belief. For, it's far from clear that there are standing moral obligations concerning how one forms beliefs in general. So, in the main text, I consider epistemic norms governing belief, where the relevant ought is understood to be epistemic. 
to the derivative norms for belief would provide an adequate account of blameless norm violation.

However, a difficulty for this approach arises from the fact that there is disagreement not only about the primary but also the derivative norms for belief. For instance, some who defend knowledge as the primary norm of belief endorse a derivative evidence norm, but deny that false beliefs can conform to the evidence norm. In particular, some defending the knowledge norm endorse a factive account of evidence and a reading of the evidence norm on which one ought to believe $\mathrm{p}$ only if the evidence fully supports p, i.e. entails it (e.g. Williamson $20 \mathrm{I}_{3}$ b: 92 ). 9 But, of course, truths can never entail a falsehood. On this view, the teacher's belief that the curry does not contain peanuts does not meet the evidential norm for, of course, it is false. Thus, the suggested knowledge-norm view cannot allow that the teacher meets the suggested condition for being excusable for giving the child the curry.

Notice that it's no accident that defenders of knowledge as the primary norm for belief endorse the suggested entailment reading of the evidence norm. For, it seems to be their best way of dealing with cases in which one has strong but non-entailing evidence supporting a falsehood. Such cases might seem to show that the knowledge norm for belief is in conflict with the platitude that one ought to conform one's beliefs to the evidence. The knowledge norm defender can avoid this objection by understanding that platitude as holding that one ought to believe $\mathrm{p}$ only if the evidence fully supports $\mathrm{p}$, where full support requires being entailed by the evidence. ${ }^{10}$

We've seen, then, that without first settling the question of what is the epistemic norm for belief, it's difficult to explain blameless violation of a norm, N, by appeal to a false belief that one's not violating $\mathrm{N}$ where that false belief conforms to the norm(s) for belief. For, on certain accounts of the norm for belief, a false belief that one's not violating the relevant norm violates either the primary or the derivative norm for belief. For example, on a prominent development of the idea that knowledge is the norm of belief, any false belief violates the primary norm for belief and the derivative evidential norm for belief. So the condition allegedly necessary and sufficient for blameless norm violation is never satisfied. On the assumption that there are some cases of blameless norm violation, the relevant condition is not necessary. Furthermore, to the extent that it is plausible that nonculpable false belief that one is not violating the relevant norm is sufficient to explain some actual examples of blameless norm violation, we need a different understanding of this sufficient condition on which it is instantiated.

9 More heroically, Sutton denies that evidence can support a false proposition (2007: I 29).

Io A defender of the knowledge-norm for belief might suggest that the knowledge norm generates various derivative norms, none of which should be understood as the norm that one ought to conform one's beliefs to the evidence. For instance, Williamson (Forthcoming) suggests that any norm, N, generates derivative norms to the effect that one ought to be disposed to conform to $\mathrm{N}$, and disposed to do what someone disposed to conform to $\mathrm{N}$ would do in the circumstances. This framework is supposed to allow that a brain in the vat who falsely believes that she has hands violates the knowledge norm for belief, but nonetheless meets the derivative norms. I raise some problems for this view in Brown (Forthcoming). But notice that if this framework is to allow that a false belief can meet the derivative norms for belief, it must be understood as denying that there is a derivative evidence norm governing belief understood as distinct from one of the relevant dispositional norms. For, on the relevant knowledge-norm view, a false belief cannot conform to the evidence norm. 
One response would be to abandon the effort to provide an account of blameless norm violation before first settling the issue of what is the epistemic norm for belief. ${ }^{\mathrm{II}}$ But, to do so might seem premature at this stage. One might still hope that one can defend some account of blameless norm violation without first settling what is the epistemic norm for belief. So let's consider some other options.

It might be suggested that we should explain blameless violation of $\mathrm{N}$ by appeal to a false but blameless belief that one is not violating $\mathrm{N}$. If we are leaving open what is the epistemic norm of belief, then we need to accommodate the popular view that the primary norm of belief is factive. On a factive view, any false belief violates the norm for belief. So if the primary norm for belief is factive, then we are explaining what it is to blamelessly violate a norm by appeal to the notion of blamelessly violating the norm of belief. But, what we were seeking for was a common account of blameless norm violation applicable to belief and action. So, this approach presupposes what it was supposed to explain. This problem undermines both the suggestion that blameless false belief that one's not violating a norm is sufficient for blameless norm violation; and, the suggestion that it is necessary.

In addition, when the account is applied to an example of a blameless violation of the norm for belief, the necessity direction quickly produces a regress. ${ }^{\mathrm{I} 2}$ Suppose for illustration that truth is the norm for belief and one falsely believes that p. According to the proposed account one is blameless in believing that $\mathrm{p}$ only if one blamelessly believes that one's belief that $\mathrm{p}$ is true. Call the latter belief the belief that $\mathrm{q}$. Of course the latter belief itself violates the truth norm for belief. So, by reapplication of this account, one is blameless in believing that q only if one has a third blameless belief to the effect that one's belief that $\mathrm{q}$ is true. But, the latter belief is false and so, by reapplication of the account, the third belief is blameless only if one has a fourth blameless belief and so on. Thus, the necessity direction of the suggested account of blameless norm violation is problematic. ${ }^{\mathrm{I}} 3$

We have now considered several ways of understanding blameless norm violation by appeal to non-culpable false belief that one's not violating the relevant norm. We've seen that it's hard to do so without first settling the question of what is the epistemic norm for belief. On a first suggestion, a non-culpable false belief is one which doesn't violate epistemic norms. But, if the norm for belief is factive, then any false belief violates this norm. In addition, on a prominent development of the knowledge norm for belief, any false belief also violates the derivative norm that one ought to conform one's beliefs to the evidence. So, on these views of the norm for belief, the condition allegedly necessary and sufficient for blameless norm-violation is never satisfied. This undermines both the sufficiency and necessity direction of an account of blameless norm violation in terms of non-culpable belief. On a second reading, a non-culpable false belief is a blameless belief. But, if the norm for belief is factive, any false belief violates the norm for belief.

I I For instance, one might first defend a justification norm for belief, and then argue that one blamelessly violates the norm, $\mathrm{N}$, when one falsely believes one is not violating $\mathrm{N}$ where that false belief conforms to the justification norm. This would give rise to the same issues raised in the later discussion of the idea that a norm violation is blameless if one justifiably believes that one is not violating it.

I2 Thanks to Joanna Schnurr for making this point in conversation.

I 3 It might be wondered whether the regress problem could be overcome by appealing to the notion of blameless ignorance that one is violating a norm, where such ignorance is understood as blameless lack of belief that one is violating. But we've already seen problems for lack of belief views above. In addition, on a bi-conditional truth norm, failing to believe a truth constitutes a norm violation. Thus this view too may presuppose the notion to be explained, namely that of a blameless norm violation. 
So, on a factive account of the norm for belief, the second suggestion amounts to attempting to explain blameless norm violation by appealing to the very idea of blameless norm violation. This is unilluminating in either the sufficiency or necessity direction. In addition, we've seen that the necessity direction generates a regress when applied to blameless violations of the norm of belief.

The problems in understanding blameless norm violation by appeal to non-culpable belief might motivate someone to suggest that we should instead understand blameless norm violation by appeal to standard epistemic notions, such as its being probable on the evidence or having justification to believe that one's not violating a norm, or not knowing that one is violating the norm etc. I turn to consider that suggestion in the next section.

\section{JUSTIFICATION, EVIDENCE, AND KNOWLEDGE - SUFFICIENCY PROBLEMS}

On the proposal to be considered, one blamelessly violates the norm, N, if and only if one has a certain epistemic standing with respect to whether one's violating that norm. One might suggest that one is blameless in violating a norm, $\mathrm{N}$, if and only if one justifiably believes, or has justification to believe, that one's not violating it (e.g. Arpaly 2002: I03-4). Alternatively, one might suggest that one is blameless in violating a norm, N, if and only if it's probable on the evidence that one's not violating it. On a different view, one is blameless in violating a norm if and only if one doesn't know that one's violating it or isn't in a position to know that one's violating it. While understanding blameless norm violation by appeal to justified belief, probability on the evidence, or knowledge looks initially plausible, difficulties arise for both its sufficiency and necessity directions.

As is well-known, there are counterexamples to the sufficiency direction of lack of knowledge versions. To see this, suppose that one violates the norm $\mathrm{N}$ while being in a Gettier situation with respect to the claim that one is violating N. One justifiably and truly believes that one is violating $\mathrm{N}$, but one neither knows that one is, or is in a position to know that one is, because one is in a Gettier case. Nonetheless, it doesn't follow that one is blameless for violating the norm. For instance, suppose that one is in a Gettier situation with respect to the claim that this sandwich contains peanuts so that one truly believes it contains peanuts where one's evidence strongly supports this. If one nevertheless feeds it to a known-to-be peanut-allergic child, one is blameworthy even though one didn't know and wasn't in a position to know that it contains peanuts. It's for this reason that the kind of ignorance which can excuse is best understood as a lack of belief rather than a lack of knowledge (Peels 20IO; Harman 20II).

In addition, we might have concerns about the sufficiency direction of the probability on the evidence and justification versions. One concern arises if one accepts that evidence can make a claim probable or justified without giving it probability I. Suppose, for example, that a claim's being .95 likely on the evidence is sufficient for it to be probable on the evidence or justified. On this view, if the probability on the evidence that this candy bar does not contain peanuts is .95 , then it's .95 likely on one's evidence that giving it to a known-to-be peanut-allergic child will not cause any harm. Nonetheless, one would not be blameless for giving the candy to the child, resulting in a fatal allergic reaction. So, it's being probable on the evidence, or one's being justified, in thinking that one is not causing harm to the child is not sufficient for one to be blameless. 
A defender of the justification account might attempt to reply in several ways. First, she might try to deal with the case by appeal to the knowledge norm for action. She might suggest that, in the described circumstances, the teacher doesn't know the curry contains peanuts and so she violates the knowledge norm for action by acting on the claim that it contains peanuts. But, we needn't understand the case as one in which the teacher does act on the proposition that it contains peanuts. For instance, she might consider the issue of allergies but dismiss it for poor reasons (e.g. reasoning that while it's .05 likely this curry will harm one of the children, I can't be bothered with that, so I'll hand out the curry to the whole class). She's still blameworthy even though she did not act on an unknown proposition.

Second, a defender of a justification account of blameless norm violation might attempt to reply to the peanut case by suggesting that the case mis-describes the relevant norm governing the teacher's action: the relevant norm is not avoiding harm, but avoiding the risk of harm. If the relevant norm governing the teacher's action is to avoid the risk of harm, then as she gives the child the curry, she knows that she is risking harm to the child. For, her evidence leaves open a small chance that the curry contains peanuts. Thus, she does not have justification to believe that she is conforming to the norm for action, when that norm is properly understood. So, the case doesn't present a counterexample to the justification account of blameless norm violation.

However, this move won't solve the fundamental underlying problem for the justification account. Whatever is the best account of the norms governing action, one's evidence about whether one's violating the relevant norm might come apart from whether one is. That's so even if the relevant norm governing action is to avoid the risk of harm. For, one's evidence about the likelihood of harm can come apart from the actual likelihood of harm. That's obviously so for objective notions of likelihood. But, many would hold that it's also the case for evidential notions of likelihood. For, they hold that one's total evidence can be misleading about what the evidence supports (e.g. Lasonen-Aarnio Forthcoming; Weatherson Forthcoming). Thus, on any account of the objective norms, there will be cases in which one violates a norm, $\mathrm{N}$, but it is probable on the evidence that one is not violating it. In some such cases, one might not be blameless for the violation. For instance, consider the norm: give food to a peanut-allergic child only if there is no chance that it contains peanuts. It might be very probable on one's evidence that there is no such chance even though there is in fact a chance. So one might violate the relevant norm, since there is a chance, although it's highly probable on one's evidence that there is no chance. If the stakes are high enough, one is blameworthy since one's evidence leaves open the small chance that one is exposing the child to risk. But, if the stakes are high enough, it seems you shouldn't run even a risk of a risk.

It seems, then, that it's not obvious that one can deal with the peanut curry case either by appeal to the knowledge norm of action, nor by appeal to the idea that the relevant norm concerns the risk of harm not actual harm. In the light of this, some might be tempted by a third response which combines fallibilism with pragmatic encroachment. According to pragmatic encroachment about justification, the strength of epistemic position required for justification varies with the stakes. ${ }^{14}$ As a result, a defender of pragmatic

I 4 This is one way of interpreting Guerrero's (2007) idea that we have moral obligations in the management of our beliefs which are sensitive to what's morally at stake. Pragmatic encroachment not only offers a way of dealing with the peanut case, but perhaps some other problematic cases of subjects 
encroachment could argue that, given how important it is not to feed peanuts to a peanut-allergic child, the teacher does not have justification to believe that the curry does not contain peanuts even when it's .95 probable on her evidence that it does not contain peanuts. Thus, on the proposed view, the peanut case would not constitute a counterexample to the justification approach to blameless norm-violation. However, a downside of this response is that pragmatic encroachment is a highly controversial view, which many find deeply unattractive. Thus, many epistemologists would be motivated to search for an account of blameless norm violation which does not involve commitment to pragmatic encroachment.

In conclusion, serious questions can be raised about the sufficiency direction of epistemic accounts of blameless norm violation whether they appeal to probability on one's evidence, justification to believe, or lack of knowledge. In addition, as we will now see, the necessity direction of such epistemic accounts is challenged by a widely discussed case in the ethics literature, due to Frank Jackson. These cases show that one can blamelessly do something while knowing that it's not what one ought to do, justifiably believing it is not what one ought to do, or its being probable on the evidence that it's not what one ought to do.

\section{JUSTIFICATION, EVIDENCE, AND KNOWLEDGE - NECESSITY PROBLEMS}

In Jackson's case Jill is faced with the choice of giving one of three drugs to a patient or doing nothing at all. Drug A would completely cure John; drug B would give him a partial cure; drug $\mathrm{C}$ would kill him; and doing nothing would leave him permanently incurable. ${ }^{\mathrm{I}} 5$ For the sake of argument, let's assume that the consequences for John determine what's best and what's best determines what Jill objectively ought to do. Thus, what Jill objectively ought to do is to give John drug A. However, the crucial complication of the case is that Jill's evidence does not tell her which of the drugs would provide a complete cure. In particular, while all of Jill's evidence indicates (in keeping with the facts) that giving John drug B would cure him partially and giving him no drug would render him permanently incurable, her evidence leaves it completely open which of drug A and drug C would cure him completely and which would kill him. In the light of this evidence, Jill gives John drug $\mathrm{B}$, thereby providing him with a partial cure. Thus, Jill does not do what she objectively ought to do. Nonetheless, intuitively we would not blame her for failing to do what she objectively ought to do. Indeed, we might think she made a good choice and acted well. If we were in John's position, we would want Jill to have acted in the same way. Some may want to say that there is a subjective sense of ought in which Jill did what she subjectively ought to have done (e.g. Zimmerman 20I4). Others may want to say

who seem blameworthy for their actions, even though, arguably, their evidence makes it probable that their actions don't violate the relevant norms. This might help with, for instance, a 1950 s American sexist who trusts the testimony of his elders that women don't have the ability to be mathematicians, hasn't come across anyone who dissents from this opinion, and doesn't have much direct evidence of female mathematicians. While his evidence supports his sexist views, given what's potentially at stake in unfairly treating women, a defender of pragmatic encroachment might suggest that he is not justified in thinking he is not violating the norm of equal treatment.

I 5 Jackson (I99I: 462-3); I use Zimmerman's (20I4) presentation. 
instead that she is merely excused for failing to do what she objectively ought to do. But regardless of whether we describe what she did as doing what she subjectively ought to have done, or merely as a case in which she's excused for failing to do what she objectively ought to have done, she is clearly not blameworthy for acting in the way she did.

That Jill is not blameworthy for her action has important consequences for epistemic accounts of blameless wrongdoing. As the case is described, when Jill gives John drug $\mathrm{B}$, she believes that she is not giving him the drug which has the best consequences for him. In addition, her evidence supports that she is not giving him the drug which has the best consequences for him. For her evidence indicates that another drug - either A or C - would completely cure him. In addition, we might describe the case in such a way that she knows and justifiably believes that she is not giving him the drug which has the best consequences. Thus, if she knows that the best consequences determine what she objectively ought to do, she knows as she acts that she is not doing what she objectively ought to do. Even so, it seems that she would be blameless in giving him drug B. Thus, the case shows that the necessity direction of Blameless is false, under various substitutions for C. Recall Blameless:

Blameless: A subject is blameless for violating the non-overridden norm, $\mathrm{N}$, if and only if $\mathrm{C}$.

In particular, the case shows us that the necessity direction of Blameless is false whether we substitute for $\mathrm{C}$ any of the following: belief that one's not violating $\mathrm{N}$, justified belief that one's not violating $\mathrm{N}$, it's being probable on the evidence that one's not violating $\mathrm{N}$. In addition, the case shows that the necessity direction of Blameless is false if we substitute for $\mathrm{C}$ the condition that the subject doesn't know, or isn't in a position to know, that she is violating N. ${ }^{16}$ For, in our case, Jill is blameless even though, as she gives John drug B, she knows that she is not giving him the drug with the best consequences.

Of course, in deriving these conclusions, we made a controversial assumption for the sake of argument, namely that the consequences for John determine what's best, and what's best determines what one ought to do. However, this assumption is inessential for the conclusion that the case presents a counterexample to the necessity direction of Blameless. What's crucial to the use of the case as a counterexample to Blameless is merely that we have a case in which what one objectively ought to do comes apart from one's evidence about what one objectively ought to do. ${ }^{17}$ However what one objectively ought to do is determined, we could have a case with the structure illustrated below:

\begin{tabular}{lll}
\hline Actions & Outcome & Evidence \\
\hline A & Very good & Very good or extremely bad \\
B & Good & Good. \\
C & Extremely bad & Very good or extremely bad \\
D & Bad & Bad \\
\hline
\end{tabular}

I6 Isaacs (2014) proposes an account of the subjective ought in terms of knowledge. He argues that a deontologist should adopt the following account of the subjective ought: one is forbidden to $\alpha$ if and only if one doesn't know that $\alpha$ ing would not violate a deontological principle.

See Zimmerman from whom the table in the main text is taken (2014: 39). 
Here, we merely assume that there is a ranking of outcomes from bad to good where what one objectively ought to do is to do the action with the highest ranking, however that is determined. By contrast, one's evidence does not perfectly reflect this ranking since it leaves it indeterminate whether it is A or C which is very good or extremely bad. It seems that regardless of how one ranks outcomes and so how what one objectively ought to do is determined, we can have a case with this structure. Thus, the assumption we made that the consequences for John determine what Jill ought to do are a harmless assumption for the sake of argument.

Jackson-style cases show that if we want a unified account of blameless wrongdoing applicable to both action and belief then an account of blameless wrongdoing cannot replace condition $\mathrm{C}$ with a variety of epistemic conditions (whether belief one is not violating; justified belief one is not violating; its being probable on the evidence one's not violating; or not knowing/being in a position to know that one is violating). However, it is interesting to see whether Jackson-style cases would present difficulties even if we were merely attempting to provide an account of blameless violation of the norm for belief. In the next section I consider this issue. Of course, whether we can construct Jackson-style cases for blameless violations of the norm of belief doesn't affect the main conclusion defended so far, namely that if one wants a unified account of blameless wrongdoing applicable to both action and belief, then epistemic accounts of blameless wrongdoing are inadequate. Nevertheless, it is an interesting question in itself.

\section{JACKSON-STYLE CASES AND NORMS FOR BELIEF}

There are a variety of suggested norms for belief, including truth, evidence, and knowledge. Here, I will argue that we can provide Jackson-style cases to undermine epistemic accounts of blameless violations of the norm for belief at least where the norm is truth or evidence. However, it will turn out that it's more difficult to provide such cases if the norm is knowledge. I start by adapting Jackson's original case to present difficulties for an epistemic account of blameless violation of the norm for belief assuming that that norm is truth: one ought to believe that $\mathrm{p}$ if and only if $\mathrm{p}$.

Suppose that instead of considering how she should act, Jill is considering what to believe about drugs A and C. Let's suppose that she knows that one of A and C will kill John and one of A and C will completely cure him, but she doesn't know which since her evidence leaves this open. Now consider what she should believe about each drug individually, say about whether A will kill John. Given that her evidence leaves it open which of the drugs A and C will kill John and which completely cure him, it seems that she ought to suspend on the question of whether A will kill John, rather than either believing that A will kill John, or believing that A will not. Nonetheless, she knows that one of these beliefs is true. Thus, it seems that she ought to suspend even while knowing that an alternative doxastic option would be better in terms of the truth norm for belief. So, assuming a bi-conditional truth norm for belief, she ought to suspend even while knowing that by suspending she is violating the truth norm for belief in the sense that she is forgoing a true belief. Schematically, we have a similar structure to the original case of Jill and John. Focusing on Jill's choice of what to believe about whether A will kill John, she has the following options: 


\begin{tabular}{lll}
\hline & Facts. & Evidence. \\
\hline Believe $\mathrm{p}$ & True & p or not-p \\
Suspend on $\mathrm{p}$ & Neither true nor false & p or not-p \\
Believe not-p & False & p or not-p \\
\hline
\end{tabular}

Intuitively, Jill is doing the right thing in suspending on $\mathrm{p}$ even though she is violating the truth norm for belief since there is a truth she's failing to believe. Whether we treat Jill as justified in suspending on p, or merely excused in doing so, she is clearly blameless. So, the case shows us that one can be blameless in violating the truth norm for belief even if, when one suspends, one knows one is violating the truth norm since one knows that one is forgoing a true belief (even though one's not sure which one). Thus, by parallel reasoning to the initial Jackson case, the variant case concerning suspension shows us that it's not necessary for blameless violations of the truth norm for belief that any of the following conditions hold: one believes one is not violating it, one justifiably believes one is not violating it, it's probable on one's evidence one's not violating it, one doesn't know/isn't in a position to know one is violating it.

As with the original Jackson case, questions may be raised about whether the suspension case can be generalised beyond our initial assumption about the norm for belief. In particular, does the case undermine the various epistemic accounts of blameless norm violation on views on which the norm for belief is not truth, but something else? Initially, one might think that just as the original case can be generalised, so can the suspension case. For what's crucial to the case is that we can rank the subject's doxastic options both in terms of whether they in fact conform to the norm of belief, and in terms of what the subject's evidence tells her about whether they conform to the norm. So, we might try to generalise the original table as follows:

\begin{tabular}{lll}
\hline & Facts & Evidence \\
\hline Believe that $\mathrm{p}$ & Best & Best or worst \\
Suspend on $\mathrm{p}$ & Good & Good \\
Believe that not-p & Worst & Best or worst \\
\hline
\end{tabular}

First consider the middle column, which concerns what doxastic state is best given that $\mathrm{p}$ is true. The thought here is that given the truth norm for belief, when $p$ is true, it's best to believe that $\mathrm{p}$, and worst to believe that not-p. Suspending on $\mathrm{p}$ has an intermediate status. It is good since, although it doesn't amount to believing the truth, it doesn't amount to having a false belief either. Now let's consider the right-hand column which concerns what one's evidence tells one about what's the best doxastic state to have. When one's evidence tells one that either $\mathrm{p}$ or not-p is true, but doesn't support $\mathrm{p}$ over not-p, then one's evidence leaves it open whether believing that $\mathrm{p}$, or believing that not-p, would conform to the truth norm for belief. However, one's evidence supports the claim that suspending on $\mathrm{p}$ is good. For, one's evidence supports the claim that by suspending on $\mathrm{p}$, one misses out on believing the truth but also misses out on believing a falsehood.

Once we have described the essence of the suspension case in terms of a ranking of doxastic states from best to worst, together with a ranking of them in terms of what the 
evidence indicates, we might hope to generalise the case to any norm for belief. For we might think that, whatever is the norm for belief, there can be a difference between how various doxastic states in fact rank with respect to that norm, and what one's evidence says about how they rank. In particular, even if the norm for belief is not truth, but instead knowledge or evidence, one might think that facts about whether one knows, or whether one's belief is supported by the evidence, can come apart from evidence about whether one knows, or whether one's belief is supported by the evidence. The extent to which a belief's actual epistemic status can come apart from evidence about its status has been much discussed in the recent epistemic literature on the possibility of epistemic akrasia and defeat. So, it is worth looking at these issues in a little more detail to see whether we can indeed construct Jackson-style cases for blameless norm violation if the norm of belief is evidence or knowledge.

First, let's try to generate a Jackson-style case on the assumption that the norm for belief is evidence: one ought to believe that $\mathrm{p}$ if and only if one's evidence supports that p. In particular, consider a putative case in which there is a conflict between one's first-order evidence and one's second-order evidence about one's evidence. For instance, suppose that a detective has gathered lots of knowledge about a certain crime on the basis of which she competently deduces the true conclusion that $\mathrm{Mr}$ Big is guilty, where that conclusion is supported by the evidence. However, subsequently, a colleague comes in and provides her with evidence that, given how long she's been on shift, it's only $50 \%$ likely that her assessment that the evidence supports Mr Big's guilt is correct. In particular, her colleague provides evidence that it's 50\% likely that her evidence supports that $\mathrm{Mr}$ Big is guilty, and $50 \%$ likely that her evidence supports that $\mathrm{Mr}$ Big is not guilty. ${ }^{\mathrm{I}}{ }^{\mathrm{It}}$ would seem that if she suspends belief about Mr Big's guilt as a result of her colleague's testimony, she is not blameworthy for doing so. However, if that's right, then at least according to one line of interpretation, the case provides a Jackson-style case in which she is blameless in suspending even though it's probable on her evidence that, by suspending, she is violating the evidence norm for belief.

To see this, focus on one main line of interpretation of the detective's case according to which it is one in which the detective's evidence is misleading about itself (e.g. Lasonen-Aarnio Forthcoming; Weatherson Forthcoming). On this interpretation, after the detective's colleague has spoken, the detective's total evidence supports Mr Big's guilt even though it also supports that it's only 50\% likely that her evidence supports that $\mathrm{Mr} \mathrm{Big}$ is guilty, and $50 \%$ likely that her evidence supports that $\mathrm{Mr} \mathrm{Big}$ is not

I 8 In order to mirror the structure of Jackson's case, it's crucial that her colleague provides evidence that it's $50 \%$ likely that the detective's evidence supports that $\mathrm{Mr} \mathrm{Big}$ is guilty and $50 \%$ likely that the detective's evidence supports that Mr Big is not guilty. Suppose, by contrast, that her colleague provides evidence that it's 50\% likely that the detective's evidence supports that $\mathrm{Mr}$ Big is guilty and $50 \%$ likely that it doesn't support that $\mathrm{Mr}$ Big is guilty. That the evidence doesn't support that $\mathrm{Mr}$ Big is guilty is compatible either with its supporting that Mr Big is not guilty, or with its neither supporting that he is guilty or that he is not. If the evidence neither supports that he is guilty nor that he is not guilty, then suspending on the question would be the best option and it would be equally bad epistemically to believe that he is guilty or believe that he is not guilty. Thus, if it's $50 \%$ likely that the evidence supports guilt and 50\% likely that it doesn't support guilt, then it's $50 \%$ likely that believing $\mathrm{Mr}$ Big is not guilty is the worst option and $50 \%$ likely that believing that he is not guilty is either the best option or a bad option. So, we no longer have the original Jackson-style case structure. 
guilty. ${ }^{19}$ If this line of thought is correct, then the case provides an example in which the ranking of the detective's possible doxastic states in terms of whether they in fact accord with the evidence norm for belief comes apart from a ranking in terms of whether her evidence supports that they so accord. In particular, the following table would describe the detective's doxastic options in terms of their actual ranking with respect to the evidence norm and the subject's evidence about how they so rank (where $\mathrm{p}$ is the proposition that Mr Big is guilty):

\begin{tabular}{lll}
\hline & $\begin{array}{l}\text { Ranking by evidence norm, } \\
\text { given the fact that evidence } \\
\text { supports believing } \mathrm{p}\end{array}$ & $\begin{array}{l}\text { Ranking by evidence } \\
\text { about conformity with } \\
\text { evidence norm }\end{array}$ \\
\hline $\begin{array}{l}\text { Believe that } \mathrm{p} \\
\begin{array}{l}\text { Suspend on } \mathrm{p} \\
\text { Believe that not-p }\end{array}\end{array}$ & $\begin{array}{l}\text { Best } \\
\text { Good }\end{array}$ & $\begin{array}{l}\text { Best or worst } \\
\text { Good } \\
\text { Best or worst }\end{array}$ \\
\hline
\end{tabular}

Given the evidence norm for belief and that the detective's evidence in fact supports believing $\mathrm{p}$, believing $\mathrm{p}$ is the best doxastic option, believing that not-p is the worst and suspending has a middle value. Now consider that it's 50\% likely that her evidence supports that $\mathrm{p}$ and $50 \%$ likely that her evidence supports that not-p. Given this, it's 50\% likely that believing that $\mathrm{p}$ is believing what the evidence supports, and $50 \%$ likely that believing that $\mathrm{p}$ is believing what the evidence does not support. Similarly, it's $50 \%$ likely that believing that not-p is believing what the evidence supports, and $50 \%$ likely that believing that not-p is believing what the evidence does not support. Thus, given her evidence about what her evidence supports, believing that $\mathrm{p}$ and believing that not-p are either the best or worst doxastic options, but her evidence leaves it open which. By contrast, whatever the evidence supports, suspending has a middle value given that it amounts to avoiding believing what's not supported by the evidence, but also doesn't amount to believing what is supported by the evidence. Thus, it seems that Jackson-style cases will occur even if the relevant norm for belief is evidence rather than truth. As a result, even if evidence is the norm, we can have cases in which a subject is blameless to suspend on $\mathrm{p}$ even though it's probable on her evidence that, by suspending, she violates the evidence norm of belief since she misses out on a belief which is supported by the evidence (either believing that $\mathrm{p}$, or believing that not-p, but her evidence leaves it open which). Similarly, we can have a case in which a subject is blameless to suspend on $\mathrm{p}$ even if she justifiably believes that

I9 Some deny the possibility of cases in which evidence is misleading about itself in the sense that one's evidence supports $\mathrm{p}$ and supports that it's not the case that one's evidence supports $\mathrm{p}$. On this view, the detective's first-order and higher-order evidence line up: either (I) her evidence supports Mr Big's guilt and supports that her evidence supports Mr Big's guilt; or, (2) her evidence does not support Mr Big's guilt and supports that her evidence does not support Mr Big's guilt. On (2) it's hard to see why the detective would be blameless if she were to violate the evidence norm of belief by believing that $\mathrm{Mr}$ Big is guilty. However, on (I) we may get problems for epistemic accounts of blameless norm violation. Arguably, the detective would be blameless if she suspends on the question of Mr Big's guilt in the light of her colleague's evidence. But if she is blameless in suspending that would undermine epistemic accounts of blameless norm violation. For since the detective's evidence supports that the evidence supports Mr Big's guilt, it is probable on the detective's evidence that she is violating the norm of conforming her belief to the evidence. 
by suspending she's violating the evidence norm, or is in a position to know that, by suspending, she is violating the evidence norm.

One might think that one could generalise the result to the view that knowledge is the norm for belief at least on the assumption that one can have misleading evidence about whether one knows. For, then, what the knowledge norm for belief in fact recommends one to believe can come apart from one's evidence about what it recommends. However, it turns out to be tricky to generate Jackson-style cases from classic cases in which one has improbable knowledge. For example, consider Williamson's recent cases of improbable knowledge (20I4). In his cases, given the limits of her discriminatory capacities, a subject knows that, say, the pointer on a dial is within a certain range (or q), although it's improbable on her evidence that she does. Given that she does know that $\mathrm{q}$ and assuming Williamson's equation of evidence and knowledge, it is therefore part of her evidence that q. But, since $\mathrm{q}$ is the strongest proposition she knows, she might be anywhere within the relevant range. But, most of the positions within the relevant range are such that if she is at those positions, she doesn't know. Thus, although she knows, it's not probable on her evidence that she knows.

Unadapted, such cases don't give us what we want. For, of course, if the subject does know that q, then her belief that q conforms to the knowledge norm. However even if we adapt such cases to suppose that the subject suspends on q, they still don't give us a Jackson-style case. ${ }^{20}$ An initial difficulty is that part of the reason why, in the original case, it's improbable that the subject knows that $\mathrm{q}$ is that she does know that $\mathrm{q}$ and so $\mathrm{q}$ is part of her evidence. If she suspends on q, then of course she doesn't know that q. So, if evidence is knowledge, $\mathrm{q}$ is not part of her evidence.

On a related knowledge-centric view of evidence, q may be part of her evidence even if she suspends on q. In particular, consider the suggestion that if one is in a position to know that $\mathrm{p}$, then $\mathrm{p}$ is part of one's evidence. As the case is described, she is in a position to know that q even if she suspends on the issue. However, even if we allow that $q$ is part of her evidence, we still don't get a Jackson-style case. The structure of Jackson-style cases for belief requires a subject blamelessly suspending on $\mathrm{p}$ while knowing that either believing that $\mathrm{p}$ would constitute knowledge or believing that not-p would constitute knowledge, but she doesn't know which. But if q is part of her evidence, then there is zero possibility on her evidence that believing that not-q would be true or constitute knowledge. So, she would know that either believing that q or believing that not-q would constitute knowledge only if she knows that believing that q constitutes knowledge. But if she does know that, she can hardly be blameless in suspending on q.

The difficulties with using Williamson's cases of improbable knowledge to generate Jackson-style cases for belief may motivate one to investigate whether other kinds of examples could generate Jackson-style cases. What's key to a Jackson-style case is that the subject blamelessly suspends on $\mathrm{p}$ while knowing that either believing that $\mathrm{p}$ would constitute knowledge or believing that not-p would constitute knowledge, but not

20 For the suspension to be a violation of the knowledge norm, we might need a slightly different formulation of the knowledge norm than the original wide scope formulation (one ought: believe that $\mathrm{p}$ if and only if one knows that p). For example, we might try the following alternative formulation. One ought believe that $\mathrm{p}$ if and only if were one to believe that $\mathrm{p}$, one's belief would constitute knowledge. It is controversial how to formulate the knowledge norm, but I leave these issues aside in this paper. 
knowing which. One might wonder if one could be in this position by trusting an oracle. For instance, suppose that the only evidence one has regarding $\mathrm{p}$ comes from an oracle which tells one that either believing that $\mathrm{p}$ constitutes knowledge or believing that not-p constitutes knowledge, but doesn't say which. Assuming that the oracle is in fact reliable and that one has good evidence of its reliability, one can gain knowledge from the oracle. So, if one suspends on the question of $\mathrm{p}$, one might seem to be in a Jackson-style case.

Nonetheless, difficulties arise. First, whether some belief constitutes knowledge depends on how it was formed. So, presumably, for what the oracle says to be true, it needs to be the case not only that there is some truth about whether $\mathrm{p}$, but also that whatever the truth is, if one were to believe it, one would have arrived at that belief in a knowledge-yielding way. For at least some propositions, this seems to involve backtracking counterfactuals. For instance, suppose that the relevant proposition is one which would require empirical investigation to know. Thus, for it to be true that if one were now to believe it, one would know it, we must suppose that one previously carried out all the relevant empirical investigation. However, there may be some propositions which can be known in a moment, perhaps in a flash of insight. So, if the oracle's testimony concerned some such proposition, perhaps we can make better sense of the claim that if one were now to believe it, one would know it. Even then, there is some risk that by having the flash of insight, one would be gaining new evidence, evidence after receiving which one would no longer be blameless in suspending on the relevant proposition. So, there would be a question of whether there is any time at which the Jackson-style structure applies: a single time at which one both blamelessly suspends on the relevant issue while also knowing the disjunction (either it's the case that if one were now to believe that $\mathrm{p}$, then one would know that $\mathrm{p}$; or, if one were now to believe that not-p, then one would know that not-p).

Thus, it is more tricky to produce Jackson-style cases for the knowledge norm of belief than it is to produce them for the truth norm or the evidence norm. The reasons for this aren't hard to see. For any proposition, $p$, it is sufficient for one to believe truly that $\mathrm{p}$ that one believes that $\mathrm{p}$ and $\mathrm{p}$ be true. It doesn't matter how one forms that belief. Similarly, for any proposition, $\mathrm{p}$, that either is or is not supported by the evidence, it is sufficient to form a belief that is supported by the evidence, that one believes that $\mathrm{p}$ and the evidence in fact supports it. Again, it doesn't matter how one forms that belief. ${ }^{21}$ But, conforming to the knowledge norm doesn't merely require true belief and a cooperative world, but depends crucially on how one formed the relevant belief.

In conclusion, we have seen that it is easy to provide Jackson-style cases at least for some suggested norms for belief, including truth and evidence. Thus, even if one's ambition is merely to provide an account of blameless norm-violation for the norm of belief, epistemic accounts would be problematic at least for certain popular accounts of the norms for belief. It seems harder to provide such cases if the norm for belief is knowledge, although I've not shown that it's impossible to do so. Nonetheless, the difficulty of generating Jackson-style cases if knowledge is the norm of belief does not undermine the main conclusion reached so far: to the extent that one is interested in an account of blameless

2I Of course, how one forms the belief might affect whether it is suitably based on the evidence. One might argue for a reading of the evidence norm for belief that requires not only evidential support but also a suitable basis. In that case, producing Jackson-style cases for the evidence norm would raise some of the same problems as producing them for the knowledge norm. 
norm violation which can apply to both belief and action, Jackson-style cases show that none of the following conditions are necessary for blameless norm violation: its being probable on the evidence that one is not violating the norm, that one is justified to believe one is not violating it, that one doesn't know/isn't in a position to know that one is violating it. When combined with the earlier objections to the sufficiency of such conditions for blameless norm violation, this motivates an examination of other accounts. In particular, some in the ethics literature have suggested that the best way to give an account of blameless violations of norms governing action is to appeal to decision theory. I examine the suggestion in the next section.

\section{APPEAL TO DECISION THEORY}

In the ethics literature, some have suggested that the best way to give an account of blameless violations of norms governing action is to appeal to decision theory. On the simplest such solution, one is blameless in failing to do what one objectively ought to have done if one nonetheless maximises expected value, where that is a function of the probability of the possible outcomes and their actual values. Appeal to expected value would explain why, in Jackson's drug case, one is blameless in failing to do what one objectively ought to do, i.e. give the drug which gives maximum benefit to the patient. ${ }^{22}$

Appeal to decision theory may be attractive in the case of action, but is problematic in the case of belief. It is widely agreed in epistemology that one epistemically ought not believe $\mathrm{p}$ when $\mathrm{p}$ is not supported by the evidence, regardless of the expected value of believing that $\mathrm{p}$. While the most obvious examples illustrating this usually involve expected value understood in non-epistemic terms, we can make the same point even using examples in which expected value is understood in terms of some epistemic good. For example, consider a Pascal-style wager argument for belief in God. At the heart of Pascal's argument is the idea that the expected value of believing in God is higher than the expected value of agnosticism or believing God does not exist given the relative costs and benefits of these different doxastic options under the hypothesis that God exists and the hypothesis that God does not exist. Suppose that the costs and benefits have the structure depicted in the table below:

\begin{tabular}{lll}
\hline & God exists & God does not exist \\
\hline Believe in God & Massive gain & Small loss \\
Suspend on whether God exists & Big loss & Small loss \\
Believe that God does not exist & Massive loss & Small positive \\
\hline
\end{tabular}

If the evidence leaves it .5 likely that God exists, then the expected value of believing in God is higher than either disbelieving or suspending on the question. Nonetheless, given that it's only .5 likely that God exists, one epistemically ought not believe in God.

22 An alternative view within the same broad approach is defended by Zimmerman (2OI4) who argues that what one subjectively ought to do is, roughly speaking, to maximise projected value which is a function of the probability of the possible outcomes and the probability (rather than the actual) values of those outcomes. 
Notice that this conclusion is not altered even if we exchange the traditional costs and benefits of belief in God, namely heaven and hell, for some non-traditional costs and benefits understood in epistemic terms. For instance, the conclusion that one epistemically ought not believe in God remains unaltered even if the relevant God would give as a benefit to his believing subjects merely epistemic rather than heavenly goods, and would give as a cost to his disbelieving subjects merely epistemic costs rather than hellish costs. For example, perhaps he would give to his believing subjects many epistemic virtues and conducive epistemic conditions so that they would accumulate masses of knowledge without gaining many false beliefs; but he would give to his disbelieving subjects many epistemic vices and unconducive epistemic conditions so that they would accumulate masses of false beliefs but few truths. Thus, Pascal's Wager provides a case in which a subject epistemically ought not believe in God even if, by doing so, she maximises expected value or even maximises expected epistemic value.

In order to turn this into a counterexample to the expected value account of blameless norm violation, we need to tweak the case a little. Recall that according to the expected value account, a subject is blameless for violating the non-overridden norm, $\mathrm{N}$, if and only if by doing so she maximises expected value. So, to turn the case into a counterexample to this expected value account we need to ensure that it's a case of blameworthy violation of a non-overridden norm. On a standard view, epistemic norms are incommensurable with instrumental norms of prudence and so not overridden by them (e.g. Feldman 2000; Kelly 2003). ${ }^{23}$ Further, we can easily turn the case into one in which the subject would violate the norm for belief if she believes in God. In particular, on the assumption that the norm for belief is factive, we can make it the case that believing in God's existence would violate the norm for belief by simply assuming that God does not exist. Thus, if the subject believes in God, she is violating a non-overridden factive norm for belief. However, given that it's part of the case that her evidence leaves God's existence at .5, she is intuitively blameworthy for believing that God exists. Furthermore, those who endorse the factive norm for belief would accept this verdict for they accept that there is a derivative norm according to which one ought not believe what is not supported by the evidence. Thus, we have a case in which a subject's belief constitutes a blameworthy violation of the non-overridden norm for belief even though, by having that belief, she is maximising expected value, whether prudential or purely epistemic. Thus, the sufficiency direction of the expected value account of blameless norm violation is false: one can be blameworthy for violating the norm of belief even if, by doing so, one maximises expected value.

The case can also be tweaked to provide a counterexample to the expected value account of blameless norm violation on the assumption that the primary norm for belief is to conform one's beliefs to the evidence. If the primary norm for belief is to conform one's beliefs to the evidence, then the case as initially described is one in which the subject violates the norm for belief by believing in God's existence. As before, this norm for belief is not overridden by instrumental norms since it is incommensurable with them. Furthermore, the subject's violation of the primary norm for belief seems blameworthy from an epistemic point of view. For, she knows that the evidence does not support his

23 As Kelly (2003) notes incommensurability would be false on instrumentalist accounts of rationality, e.g. Foley (I987), Kitcher (I992), Kornblith (I993), Nozick (I993), and Lauden (I996). But such accounts face serious objections. 
existence. Thus, she knows that she is violating the evidence norm for belief. Thus, the case challenges the sufficiency direction of the expected value account of blameless norm violation.

Thus, Pascal Wager-style cases can be used to challenge the sufficiency direction of the expected value account of blameless norm violation whether the norm of belief is truth, knowledge, or evidence. Furthermore, Pascal wager cases can be used to challenge the necessity direction of the expected value account at least on some accounts of the norm for belief. In particular, one can blamelessly violate the norm for belief even if one does not maximise expected value. For instance, if in a Pascal-style case, one suspends on the existence of God, one seems blameless. Given the structure of the case, suspending on the existence of God does not maximise expected value. Assuming there is some truth about whether God exists, then at least on a bi-conditional truth norm for belief, one violates that norm by suspending. So, we have a case in which one blamelessly violates the truth norm for belief by suspending on the existence of God where that suspension does not maximise expected value. So maximising expected value is not necessary for blamelessly violating a norm.

It seems, then, that while appeal to expected value can seem attractive within the project of giving an account of blameless violation of the norms for action, it is not suitable as an answer to the project of giving an account of blameless violation of the norms for action or belief.

\section{CONCLUSION}

We've examined three broad approaches to providing an account of when one is blameless for violating a norm: that one is (non-culpably) ignorant that one is violating a norm; that one has a certain epistemic standing with respect to whether one is violating the norm (whether probability on the evidence, justification, or lack of knowledge); or appeal to decision theory. While all three main approaches have support in the literature, we have seen that they are not plausible when considered as accounts of blameless norm violation applicable to both norms governing actions, and norms governing belief. In particular, the sufficiency direction of expected value accounts of blameless norm violation fails for blameless violation of the norm of belief, whether the norm of belief is truth, knowledge, or evidence. The necessity direction of epistemic accounts fails due to Frank Jackson cases. These arise most obviously for action, but also arise for belief at least if the norm for belief is truth or evidence. In addition, we raised questions about the sufficiency direction of epistemic accounts. Whether appeal to non-culpable false belief that one's not violating a norm provides an adequate account of blameless norm violation depends on what is the correct account of the epistemic norm for belief. One might try to explain non-culpable false belief as belief that doesn't violate either the primary, or derivative, norms for belief. But, if the primary norm for belief is factive, then any false belief is a violation of the primary norm for belief. In addition, on one prominent development of the knowledge norm for belief, any false belief also violates the derivative norm of conforming one's belief to the evidence. So, the proposed necessary and sufficient condition for blameless norm violation is never satisfied. Alternatively, if one appeals to the notion of blameless false belief without explaining it, one seems to presuppose what we are searching for, namely an 
account of blameless norm violation. For, of course any false belief violates the primary norm for belief at least if that norm is factive.

In the light of these results, there seem to be three broad main ways forward. First, one could explore whether some other approach to blameless norm violation could be applied to blameless violations both of norms governing action and norms governing belief. For example, some have recently suggested that we can explain the notion of blameless norm violation by appeal to the kinds of dispositions norm-observers ought to have. Defenders of such accounts suggest that they can be applied to both norms governing action and norms governing belief (e.g. Sutton 2007; Williamson Forthcoming; for criticism see Brown Forthcoming; Kelp Forthcoming). Second, one might conclude that the project of providing an account of blameless norm violation can be sensibly pursued only after first settling the question of what is the epistemic norm for belief. Third, one might set aside the hope for an account of blameless norm violation common to violations of norms governing action and norms governing belief. Instead, one might defend the idea that different accounts of blameless norm violation are appropriate in these two areas. For instance, perhaps appeal to decision theory works better as an account of blameless norm violation for action than for belief. Which of these is the most promising response must be left to another occasion. ${ }^{24}$

\section{REFERENCES}

Arpaly, N. 2002. Unprincipled Virtue: An Enquiry Into Moral Agency. Oxford: Oxford University Press.

Brown, J. Forthcoming. Fallibilism: Evidence and Knowledge.

Calhoun, C. I989. 'Responsibility and Reproach.' Ethics, 99: 389-406.

Cohen, S and Comesaña, J. 20I 3 a. 'Williamson on Gettier Cases and Epistemic Logic.' Inquiry, 56 : I 5-29.

- 20I3 b. 'Williamson on Gettier Cases in Epistemic Logic and the Knowledge Norm for Rational Belief: A Reply to a Reply to a Reply.' Inquiry, 56: 400-I 5 .

—. Forthcoming. 'Being Rational and Being Right.' In J. Dutant and F. Dorsch (eds), The New Evil Demon. Oxford: Oxford University Press.

Feldman, F. 2000. 'The Ethics of Belief.' Philosophy and Phenomenological Research, LX: 667-95.

Fitzpatrick, W. 2008. 'Moral Responsibility and Normative Ignorance: Answering a New Sceptical Challenge.' Ethics, 6I 8: 589-6 3 3.

Foley, R. 1987. A Theory of Rationality. Cambridge, MA: Harvard University Press.

Guerrero, A. 2007. 'Don't Know, Don't Kill: Moral Ignorance, Culpability, and Caution.' Philosophical Studies, I36: 59-97.

Harman, E. 20I I. 'Does Moral Ignorance Exculpate?' Ratio, 24: 443-68.

Hawthorne, J. 2004. Knowledge and Lotteries. Oxford: Oxford University Press.

Hawthorne, J. and Srinivasan, A. 20I3. 'Disagreement Without Transparency: Some Bleak Thoughts.' In D. Christensen and J. Lackey (eds), The Epistemology of Disagreement: New Essays, pp. 9-30. Oxford: Oxford University Press.

Isaacs, Y. 20I4. 'Duty and Knowledge.' Philosophical Perspectives, 28: 95-I ro.

Jackson, F. I991. 'Decision Theoretic Consequentialism and the Nearest and Dearest Objection.' Ethics, IOI: $46 \mathrm{I}-82$. 
Kelly, T. 2003. 'Epistemic Rationality is Instrumental Rationality: A Critique.' Philosophy and Phenomenological Research, LXVI: 6I2-40.

Kelp, C. Forthcoming. 'Justified Belief: Knowledge-First Style.' Philosophy and Phenomenological Research.

Kitcher, P. I992. 'The Naturalist's Return.' Philosophical Review, IOI: 53-I I4.

Kornblith, H. I993. 'Epistemic Normativity.' Synthese, 94: 357-76.

Lasonen-Aarnio, M. Forthcoming. 'Enkrasia or Evidentialism: Learning to Love Mismatch.' Philosophical Studies.

Lauden, L. I996. Beyond Positivism and Relativism. Boulder, CO: Westview Press.

Levy, N. 2009. 'Culpable Ignorance and Moral Responsibility: A Reply to Fitzpatrick.' Ethics, I I9: 729-4I.

Littlejohn, C. Forthcoming. 'A Plea for Epistemic Excuses.' In J. Dutant and F. Dorsch (eds), The New Evil Demon. Oxford: Oxford University Press.

Mason, E. 201 5. 'Moral Ignorance and Blameworthiness.' Philosophical Studies, I72: 3037-57.

Moody-Adams, M. I994. 'Culture, Responsibility and Affected Ignorance.' Ethics, I04: 29 I-309.

Nozick, R. I993. The Nature of Rationality. Princeton, NJ: Princeton University Press.

Peels, R. 2010. 'What is Ignorance?' Philosophia, 38: 57-67.

- 20I4. 'What Kind of Ignorance Excuses? Two Neglected Issues.' Philosophical Quarterly 64: $478-96$.

Rosen, G. 2003. 'Culpability and Ignorance.' Proceedings of the Aristotelian Society, I03: 6I-84. . 2004. 'Scepticism about Moral Responsibility.' Philosophical Perspectives, I 8: 295-3 I3.

Sutton, J. 2007. Without Justification. Cambridge, MA: MIT Press.

Weatherson, B. Forthcoming. Normative Externalism.

Williamson, T. 2000. Knowledge and Its Limits. Oxford: Oxford University Press.

—. 20I3a. 'Gettier Cases in Epistemic Logic.' Inquiry, 56: I-I4.

- 2013b. 'Response to Cohen, Comesaña, Goodman, Nagel and Weatherson on Gettier Cases in Epistemic Logic.' Inquiry, 56: 77-96.

—. 20I4. 'Very Improbable Knowing.' Erkenntnis, 79: 97 I-99.

. Forthcoming. 'Justifications, Excuses, and Sceptical Scenarios.' In J. Dutant and J. Dorsch (eds), The New Evil Demon. Oxford: Oxford University Press.

Zimmerman, M. 2008. Living with Uncertainty: The Moral Significance of Ignorance. Cambridge: Cambridge University Press.

20I4. Ignorance and Moral Obligation. Oxford: Oxford University Press.

JESSICA BROWN is currently Professor of Philosophy in the Arché research centre at St Andrews University. Since her Ph.D. at Oxford University, she has worked on a wide range of topics within philosophy of mind, epistemology, and the methodology of philosophy. She is the author of Anti-Individualism and Knowledge, MIT 2004; and has co-edited several collections for Oxford University Press (Knowledge Ascriptions, 20I2; and Assertion, 20II). Since her appointment in St Andrews in 2007, she has helped lead the highly successful international philosophical research centre Arché. She was principal investigator on a major AHRC-funded project (2008-I2) examining the methodological foundations of philosophical enquiry. Since 20I3, she has been the editor of Philosophical Quarterly. 